\section{JURNAL PENGABDIAN PADA MASYARAKAT}

ISSN 2540-8739 (print) || ISSN 2540-8747 (online)

LEMBAGA PENELITIAN, PENGABDIAN, DAN PENGEMBANGAN MASYARAKAT UNIVERSITAS MATHLA'UL ANWAR BANTEN

\title{
Pengembangan Keterampilan Berpikir Positif melalui Layanan Konseling Kelompok bagi Anggota Ikatan Mahasiswa Pemuda Pelajar Semurup, Kota Padang
}

\author{
Hengki Yandri ${ }^{1}$, Alfaiz ${ }^{2}$, Dosi Juliawati ${ }^{3}$ \\ 1,3 Institut Agama Islam Negeri Kerinci, 2 STKIP PGRI Sumatera Barat
}

\begin{abstract}
Article History ABSTRACT
Received 14.09.2019 Received in revised form 29.11.2019

Accepted 04.12.2019

Available online 16.12.2019

DEVELOPING A POSITIVE THINKING SKILL OF IMPPS MEMBERS THROUGH GROUP COUNSELING SERVICE. Activities of community service was based on a phenomena about lack of student's positive thinking skill and there are not functional optimally in a positive way. The purpose of this service is to developing a positive thinking skill of IMPPS members in Padang through group counseling service. The implementation method used consist of five phase which is 1) Shaping, 2) Transition, 3) Intervention, 4) Conclusion, and 5) Closing service. A total participant was 50 students of IMPPS Member. Result of this service was a member of IMPPS Padang has a knowledge, paradigm, and positive thinking skill in their activities in social and learning.
\end{abstract}

KEYWORDS: Guidance and Counseling, Learning, Positive Thinking. Attribution 4.0 International License, which permits unrestricted use, distribution, and reproduction in any medium, provided the original work is properly cited. (c) 2019 Hengki Yandri, Alfaiz, Dosi Juliawati.

\section{PENDAHULUAN}

Pada setiap tahap perkembangan, manusia melalui berbagai perubahan baik secara psikis maupun secara fisik. Remaja merupakan salah satu masa fase perkembangan dari manusia, pada fase ini banyak terjadinya perubahan yang banyak para ahli berbeda pendapat. Akan tetapi dari berbagai pendapat bisa ditarik kesimpulan bahwa pada masa tersebut, remaja merupakan masa di mana individu manusia tersebut mencari dan melakukan internalisasi kepribadian dan berpikir yang akan banyak mengalami tantangan perkembangan yang berasal dari dalam dirinya dan bahkan dari luar dirinya seperti lingkungan sekitarnya (Yandri \& Juliawati, 2018).

Tantangan perkembangan yang dilalui pada fase remaja ini sangat kompleks, karena secara perkembangan sosial remaja mulai memisahkan diri dari orangtuanya dan mulai menjalin hubungan dengan teman sebaya (Sartika \& Yandri, 2019). Secara perkembangan

${ }^{2}$ Corresponding author: Bimbingan dan Konseling, STKIP PGRI Sumatera Barat. Jl. Gunung Pangilun, Kec. Padang Utara, Kota Padang, Sumatera Barat 25173, Indonesia. Email: alfaiz.science.icp@ gmail.com 
sosio-emosional masa remaja merupakan masa membentuk kepribadian dan mencari identitas diri, sehingga pada masa perkembangan ini banyak remaja mengalami kesulitan dalam bersosialisasi serta menjadi pribadi yang memang kurang sesuai dengan kepribadiannya (King, 2010). Hal ini dikarenakan pada periode ini remaja banyak dipengaruhi teman sebayanya. Sedangkan dari segi perkembangan kognitif, fase perkembangan kognitif remaja berada pada tahap operasional formal yang mana sudah mampu untuk berpikir abstrak dan memikirkan kehidupannya ke depan (King, 2010).

Kemampuan remaja dalam berpikir masih belum baik, karena pengalam dan pengetahuan mereka masih sangat minim. Hal ini akan membuat remaja mengalami kesulitan dalam mencari identitas sehingga perasaan dan pikiran akan semakin berat ketika mengalami kegagalan, yang muaranya remaja menemukan kebimbangan yang mengakibatkan melakukan konformitas atau melakukan penyamaan identitas diri dengan teman sebayanya (Sartika \& Yandri, 2019) mengalami ketakutan dalam berpikir, dan kekhawatiran dalam menjalankan kehidupannya karena ketakutan untuk menghadapi masa depan yang belum jelas.

Setiap individu memiliki kelebihan, kelemahan, dan kecenderungan yang berbedabeda, begitu juga pola pikir dan kebiasaan berpikir juga memiliki kecenderungan berbeda. Remaja saat ini hidup di era digital, sehingga banyak yang bisa mempengaruhi pola pikirnya dan emosinya karena orangtua dan lingkungan yang secara tidak langsung banyak mengajarkan anak-anak belajar merespons kejadian yang menimpa dirinya atau yang menimpa orang-orang di sekitarnya secara negatif (Yandri, Juliawati, Alfaiz, \& Nofrita, 2018). Remaja sebenarnya merupakan masa emas, karena pada masa ini merupakan masa puncak remaja mencari jati dirinya yang sebenarnya (the true self) bagi yang sukses akan menjadi pribadi yang baik, dan bagi yang tidak berhasil hidup dalam bayang-bayang pribadi yang lain dan tidak bisa mencapai keberhasilan di masa depan.

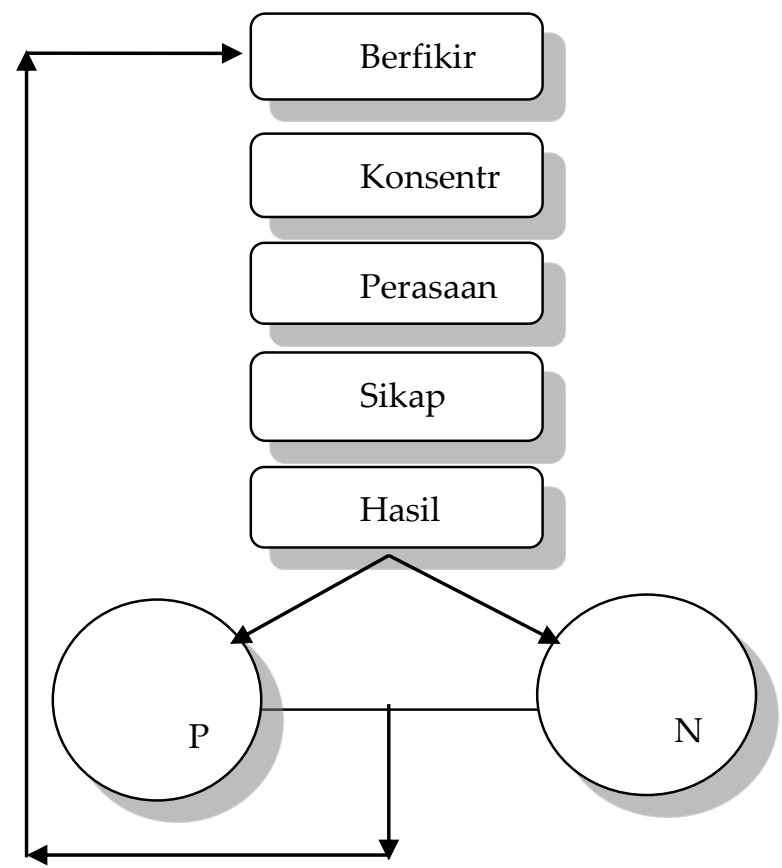

Gambar 1. Proses Berpikir 
Pola dan kebiasaan berpikir merupakan salah satu faktor adanya keberhasilan remaja dalam kehidupan masa depannya dan ada pula yang larut dengan problematika sosial dalam kehidupannya. Menurut pandangan Syekh Muhammad Mutawalli alSya'rawi dalam bukunya al-Khawathir "pikiran adalah alat ukur yang digunakan manusia untuk memilih sesuatu yang dinilai lebih baik dan lebih menjamin masa depan diri dan keluarganya" (Elfiky, 2010). Pikiran juga mempengaruhi hasil yang akan dicapai, bagaimana individu berbuat dan berperilaku sesuai dengan apa yang dia pikirkan dan apa yang dia maknai dari suatu hal. Seperti halnya bagan berikut (Elfiky, 2010).

Dalam pandangan psikologi sosial para ahli salah satunya Bandura mendefinisikan berpikir sebagai bagian penting dari terjadinya interaksi sosial yang baik dan terjadinya saling keterkatian dan menentukan antara individu dalam lingkungannya (resiprocal determination) (Walgito, 2003). Ketika lingkungan baik dan nyaman maka pola pikir individu disana positif, ketika sebaliknya maka ada hubungannya dengan cara berpikir seseorang dalam lingkungan tadi. Salah satu yang menghasilkan hal yang positif dari berpikir positif adalah kemampuan diri yang muncul ketika berpikir positif tentang kemampuan diri sendiri di masa lalu (Alfaiz, Zulfikar, \& Yulia, 2017).

Oleh karena itu sebagai pendidik, tim merasa penting mengenalkan pada remaja bahwa kemampuan berpikir sangat luar biasa pengaruhnya terhadap diri dan lingkungan tempat berinteraksi. Perlu juga diperhatikan potensi berpikir juga disokong oleh kondisi afektif emosional remaja seperti halnya role model (contoh) dalam kehidupan sosial yang dijadikan panutan ini menentukan juga pengaruh pada berpikir positif (Alfaiz, 2014). Maka untuk mendapatkan masa depan yang baik di mulai merubah pikiran dan pola pikir yang negatif menjadi positif, karena pikiran menentukan sejauh mana harmoninya individu dengan lingkungannya. Untuk mencapai kemampuan berpikir yang baik dan positif, dibutuhkan teknik dan metode yang tepat, sehingga dalam hal ini tim mencoba mengembangkan kemampuan berpikir Anggota Ikatan Mahasiswa Pemuda Pelajar Semurup (IMPPS) Kota Padang Melalui Layanan Bimbingan Kelompok.

Bimbingan kelompok merupakan salah satu layanan bimbingan dan konseling yang diselenggarakan secara kelompok yang didalamnya terjadi interaksi antar anggota kelompok untuk menambah wawasan, pengetahuan, keterampilan, nilai dan sikap yang berguna bagi pengembangan diri anggota kelompok (Juliawati, 2014). Melalui kegiatan bimbingan kelompok yang beranggotakan beberapa orang, mereka dapat saling tukar pendapat dan pengalaman, sehingga antara satu anggota dengan anggota lainnya dapat belajar mengembangkan sikap dan kebiasaan positif (Yandri, 2017).

Pemanfaatan dinamika kelompok dalam kegiatan layanan bimbingan kelompok untuk membahas suatu topik bahasan yang bermanfaat bagi anggota kelompok dengan tujuan untuk pengembangan kemampuan bersosialisasi khususnya kemampuan berkomunikasi peserta layanan serta dapat mendorong pengembangan nilai rasa, pemikiran, persepsi, wawasan dan pengetahuan, dan serta sikap untuk mewujudkan tingkah laku yang lebih efektif (Ulandari \& Juliawati, 2019). Dengan kegiatan layanan bimbingan kelompok, maka diharapkan kemampuan berpikir positif Anggota Ikatan Mahasiswa Pemuda Pelajar Semurup (IMPPS) Kota Padang menjadi lebih baik. Tujuan dari kegiatan Pengabdian kepada Masyarakat ini yaitu untuk mengembangkan kemampuan berpikir positif Anggota Ikatan Mahasiswa Pemuda Pelajar Semurup (IMPPS) Kota Padang melalui layanan bimbingan kelompok. 


\section{METODE PELAKSANAAN}

Kegiatan pengabdian kepada masyarakat ini dilakukan dengan lima tahap kegiatan yaitu sebagai berikut:

\section{Pembentukan}

Pada tahapan pembentukan ini bertujuan untuk membentuk kerumunan sejumlah individu menjadi satu kelompok yang siap mengembangkan dinamika kelompok dalam mencapai tujuan bersama dan untuk pengenalan diri, pelibatan diri dan pemasukkan diri anggota kelompok dalam kegiatan kelompok. Pada tahap ini dilakukan pemimpin kelompok mengungkapkan pengertian dan tujuan kegiatan kelompok, menjelaskan caracara dan asas-asas kegiatan, saling memperkenalkan dan mengungkapkan diri, melakukan permainan penghangatan dan penghargaan terhadap anggota kelompok.

\section{Peralihan}

Tahapan peralihan ini bertujuan untuk mengalihkan kegiatan awal kelompok ke kegiatan berikutnya yang lebih terarah pada pencapaian tujuan kelompok. Pada tahap ini pemimpin kelompok menjelaskan kegiatan yang akan ditempuh pada tahap berikutnya, menawarkan atau mengamati apakah anggota siap menjalani kegiatan selanjutnya, membahas suasana yang terjadi, dan meningkatkan kemampuan keikutsertaan anggota kalau perlu kembali ke beberapa aspek tahap pertama.

\section{Kegiatan Inti}

Pada tahap ini dibahas topik masalah yang materinya mengacu pada pengembangan kemampuan berpikir positif. Setiap anggota kelompok berperan aktif mengemukakan pendapatnya terkait dengan topik yang dibahas dalam kelompok. Topik dibahas secara mendalam, luas dan tuntas. Setiap anggota kelompok dilatih berpikir kritis, analis, sistematis dan logis, sehingga apa yang dibahas dapat melekat pada masing-masing anggota dan dapat diaplikasikannya

\section{Penyimpulan}

Tahap penyimpulan yaitu tahapan untuk mengetahui kembali apa yang sudah dilakukan dan dicapai oleh kelompok. Peserta kelompok diminta melakukan refleksi berkenaan dengan kegiatan pembahasan yang baru saja mereka ikuti. Pada tahap ini pemimpin kelompok pemimpin dan anggota kelompok mengemukakan kesan dan hasilhasil kegiatan, dan mengemukakan pesan dan harapannya setelah mengikuti kegiatan ini.

\section{Penutup}

Tahap penutupan merupakan akhir dari seluruh rangkaian kegiatan, kemudian kelompok merencanakan kegiatan selanjutnya. Dalam pembahasan frekuensi pertemuan, dibahas tentang kapan dan berapa kali pertemuan akan dilakukan. Sedangkan pada pembahasan keberhasilan kelompok, difokuskan pada komitmen anggota kelompok dalam melaksanakan kesepakatan bersama. 


\section{HASIL DAN PEMBAHASAN}

Hasil kegiatan pengabdian kepada masyarakat yang telah dilakukan kepada Anggota Ikatan Mahasiswa Pemuda Pelajar Semurup (IMPPS) Kota Padang dengan mencoba mengembangkan kemampuan berpikir Anggota IMPPS Kota Padang melalui Layanan Bimbingan Kelompok menghasilkan hal-hal sebagai berikut:

1) Anggota Ikatan Mahasiswa Pemuda Pelajar Semurup (IMPPS) Kota Padang yang mengikuti kegiatan ini yaitu sebanyak 50 orang.

2) Kegiatan ini memberikan manfaat kepada anggota IMPPS Kota Padang dalam hal keterampilan berpikir positif.

3) Sebelum anggota IMPPS Kota Padang mengikuti kegiatan ini, mereka masih cenderung menggunakan pikiran negatif dalam menilai setiap kejadian yang mereka lalui maupun yang mereka temui.

4) Dalam kegiatan layanan bimbingan kelompok, anggota IMPPS Kota Padang disuguhkan dengan berbagai fenomena yang terjadi di masyarakat, kemudian mereka diminta memanfaatkan pikiran mereka dalam memberikan penilaian terhadap fenomena tersebut dengan teknik berpikir positif yang telah dibahas.

5) Secara umum, anggota IMPPS Kota Padang mendapatkan pemahaman, wawasan dan keterampilan baru dalam berpikir positif.

6) Anggota IMPPS Kota Padang merasa sangat senang mendapatkan materi tentang pengembangan kemampuan berpikir positif melalui kegiatan layanan bimbingan kelompok, dan mereka mengharapkan kegiatan lanjutan dilakukan dengan materi pembahasan yang berbeda.

7) Anggota IMPPS Kota Padang memiliki komitmen bersama untuk mengaplikasikan ilmu, pengetahuan, wawasan dan keterampilan baru dalam memanfaatkan pikiran dengan cara yang positif pada setiap peristiwa yang mereka alami maupun yang mereka lihat.

Secara umum, faktor penunjang kegiatan ini yaitu terjalinnya kerja sama yang baik antara tim pengabdian masyarakat dengan pengurus IMPPS Kota Padang, kemudian lokasi kegiatan yang mudah dijangkau dan strategis mudah di jangkau oleh semua anggota IMPPS Kota Padang. Selanjutnya kerja sama, antusias dan kekompakan anggota IMPPS Kota Padang memberikan point plus dalam menunjang kegiatan ini berjalan dengan baik dan sesuai dengan rencana yang telah ditetapkan. Di samping faktor penunjang, terdapat juga faktor penghambat kegiatan yaitu waktu pelaksanaan yang singkat sehingga dirasa kurang optimal dalam pemberian materi dan kegiatan praktik pemanfaatan berpikir positif.

Pelaksanaan kegiatan ini ditunjang juga oleh rasa ingin tahu yang tinggi dari anggota IMPPS serta kebutuhan untuk menggali ilmu pengetahuan bagaimana berpikir positif dan bagaimana meminimalisir pengaruh emosi negatif dalam kehidupan sehari-hari. Dalam kegiatan tersebut tim melakukan brain storming untuk membuka wawasan anggota IMPPS mengenai diri mererka dengan mengenal kondisi psikis mereka, bahwa diri setiap manusia merupakan bersifat materi dan ruh, yang jika didalami pemahamannya secara transenden/hakiki maka akan muncul dorongan untuk self correction pada diri mereka agar lebih terkontrol dan terkendali (Alfaiz et al, 2019). Proses koreksi diri ini merupakan 
proses sugestif untuk mengubah persepsi diri tentang kondisi diri secara internal impulse untuk mengubah pola pikir (Zulfikar et al, 2018).

Ketika individu yang melakukan proses self correction secara transenden memunculkan will atau hasrat dalam berpikir dan berperilaku secara positif untuk mencapai tujuannya hal ini juga memiliki kecenderungan menekan dorongan ego dengan meningkatnya kemampuan kognitif yang positif (Alfaiz, Hariko, Rafiola, \& Zulfikar, 2017). Di era yang merupakan masa post-truth yaitu era dimana informasi perlu diperhatikan sumber kebenarannya karena banyaknya informasi hoax yang bisa merusak pemikiran individu, maka merupakan tantang tertentu untuk generasi muda sebagai konselor bagi dirinya (Alfaiz, 2018), untuk melakukan filter informasi sehingga melahirkan pemikiran yang positif.

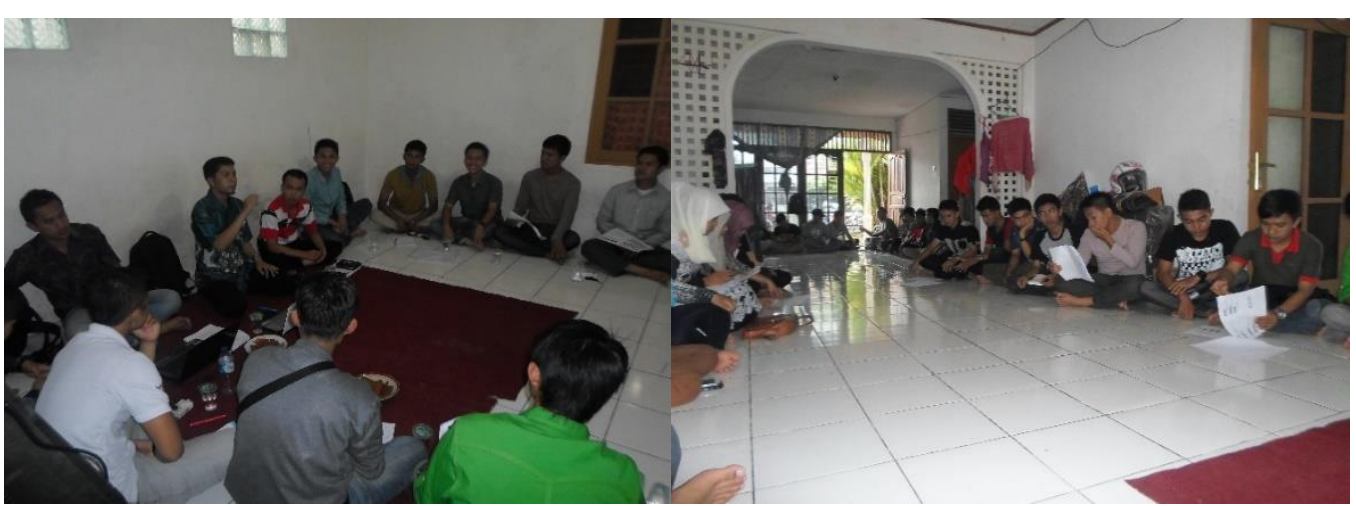

Gambar 2. Penyampaian Proses Pelaksanaan Kegiatan Layanan Bimbingan Kelompok

\section{SIMPULAN}

Secara umum anggota Anggota Ikatan Mahasiswa Pemuda Pelajar Semurup (IMPPS) Kota Padang terlibat aktif dan antusias dalam kegiatan ini dan kegiatan berjalan sesuai dengan rencana yang telah ditetapkan serta anggota IMPPS Kota Padang mendapatkan wawasan, pengetahuan dan keterampilan baru dalam memanfaakan pikiran positif, kemudian mereka juga merasa senang dengan tema materi yang diberikan dan mereka berharap kegiatan serupa dilakukan lagi. Seterusnya anggota IMPPS Kota Padang memiliki komitmen bersama untuk mengaplikasikan ilmu, pengetahuan, wawasan dan keterampilan baru dalam memanfaatkan pikiran dengan cara yang positif.

Kepada anggota IMPPS Kota Padang diharapkan dapat mengaplikasikan wawasan, pengetahuan dan keterampilan baru yang mereka peroleh dari kegiatan pengabdian kepada masyarakat yang telah dilakukan dan mempu menularkan kebaikan dan pikiran positif kepada orang lain di sekitar mereka.

\section{REFERENSI}

Alfaiz. (2014). Pembelajaran afektif merupakan salah satu strategi dalam pembentukan karakter peserta didik. Jurnal Pelangi, $7(1), \quad 94-105$. https://doi.org/10.22202/jp.2014.v7i1.152 
Alfaiz. (2018). Guidance and counseling profession: a Philosophy and professional challenges in the future. Couns-Edu: International Journal of Counseling and Education, 3(1), 44-47. https://doi.org/10.23916/0020180313420

Alfaiz., Yandri, H., Kadafi, A., Mulyani, R. R., Nofrita, N., \& Juliawati, D. (2019). Pendekatan Tazkiyatun An-Nafs untuk membantu mengurangi emosi negatif klien. Counsellia: Jurnal Bimbingan dan Konseling, 9(1), 65-78. https://doi.org/10.25273/counsellia.v9i1.4300

Alfaiz., Hariko, R., Rafiola. R.H, \& Zulfikar. (2017). Condition and shaping of student personality in educational process through transpersonal psychology perspective. Advances in Social Science, Educational and Humanities Research, 128, 1-4.

Alfaiz., Zulfikar., \& Yulia, D. (2017). Efikasi diri sebagai faktor prediksi kesiapan mahasiswa dalam mengerjakan tugas kuliah. Ilmu Pendidikan: Jurnal Kajian Teori dan Praktik Kependidikan, 2(2), 119-124.

Elfiky, I. (2010). Terapi berpikir positif. Jakarta: Zaman.

Juliawati, D. (2014). Efektivitas layanan bimbingan kelompok mengurangi prokrastinasi akademik siswa. In Prayitno, Mudjiran, Syahniar, \& M. S. Abdullah (Eds.), Pendidikan dan konseling: Kreativitas pendidik dan konselor dalam menghadapi warna-warni kehidupan. Paper presented at the International Guidance and Counseling Conferrence, UNP, Padang, Indonesia, 5-6 June 2014 (pp. 36-41). Padang: Universitas Negeri Padang dan ABKIN

King, L. A. (2010). Psikologi umum sebuah pandangan apresiatif (Science psychology). Jakarta: Salemba Humanika.

Sartika, M., \& Yandri, H. (2019). Pengaruh layanan bimbingan kelompok terhadap konformitas teman sebaya. Indonesian Journal of Counseling and Development, 1(1), 917.

Ulandari, Y., \& Juliawati, D. (2019). Pemanfaatan layanan bimbingan kelompok untuk meningkatkan kecerdasan emosi siswa. Indonesian Journal of Counseling and Development, 1(1), 1-8.

Walgito, B. (2003). Psikologi sosial. Yogyakarta: Andi Offset.

Yandri, H. (2017). Efektivitas dirasah pengembangan diri melalui pelayanan konseling dalam membentuk kecerdasan emosi mahasantri Ma'had Al Jami'ah IAIN Kerinci. Tarbawi: Jurnal Ilmu Pendidikan, 13(1), 1-10.

Yandri, H., \& Juliawati, D. (2018). Profile of the problem of the adolescent with parents as Indonesian migrant workers. Konselor, 7(4), 160-165. https://doi.org/10.24036/0201874101452-0-00 
Yandri, H., Juliawati, D., Alfaiz., \& Nofrita. (2018). Keterampilan konselor dalam melepas emosi negatif anak dengan terapi reframing. In S. Yusuf LN., \& S. Adiputra (Eds.), Mengokohkan peran program bimbingan dan konseling di perguruan tinggi dalam rangka menyongsong generasi emas tahun 2045. Paper presented at Seminar Nasional Bimbingan dan Konseling di Perguruan Tinggi, UPI Bandung, Indonesia, 6 April 2018 (pp. 167-177). Bandung: Universitas Pendidikan Indonesia dan IBKPT.

Zulfikar, Z., Alfaiz, A., Zaini, A., Suarja, S., Nofrita, N., \& Kardo, R. (2018). Counseling as a science or educational practice in multicultural philosophy dimension (A synthesize and counselor perception about counseling profession). International Journal of Research in Counseling and Education, 3(1), 1-7. https://doi.org/10.24036/0049za0002 